\title{
Case of odontoma-related infection in a cleidocranial dysplasia
}

\author{
Afonso Martins, ${ }^{1}$ Patrícia Caixeirinho, ${ }^{1}$ Ana Fernandes ${ }^{2}$
}

${ }^{1}$ Estomatologia, Hospital de Sao Jose, Lisboa, Portugal ${ }^{2}$ Estomatologia Pediátrica, Hospital Dona Estefania, Lisboa, Portugal

\section{Correspondence to}

Dr Afonso Martins, martinsjoao@campus.ul.pt

Accepted 17 May 2019

\section{DESCRIPTION}

Cleidocranial dysplasia (CCD) is a rare syndrome with an estimated prevalence of 1:1000 000. ${ }^{12}$ It has an autosomal dominant transmission with complete penetrance and variable expression, equally affecting men and women. ${ }^{3}$ This skeletal disorder is caused by a mutation in the RUNX2 (CBFA1) gene, on the short arm of chromosome 6 (6p21). ${ }^{3}$ This gene encodes a runt-related transcription factor involved in osteoblast and chondrocyte differentiation. ${ }^{3}$ The most frequent clinical features are skull deformity, hypoplastic maxilla, hypoplastic or aplastic clavicles, supernumerary teeth and delayed teeth eruption. ${ }^{3}$ Although these features may vary, normal deciduous dentition, delayed eruption of permanent teeth and multiple supernumerary teeth impaction are practically pathognomonic of CCD. ${ }^{3}$

Supernumerary teeth and odontomas (ODs) - the most frequent odontogenic benign tumours-share a common origin. ${ }^{4}$ They arise from a hyperactive dental lamina as a response to teratogenic or genetic stimuli. ${ }^{4}$ Mostly asymptomatic, both can be related with delayed tooth eruption. ${ }^{4}$ Composed of enamel, dentine and cement, ODs can be divided into compound and complex. ${ }^{5}$ While compound ODs consist of multiple little tooth-like structures usually in the anterior upper maxilla, complex ODs are single amorphous masses without structural organisation, generally found in the posterior mandible. ${ }^{5}$

Throughout the years, different ways of dental management were proposed, namely the TorontoMelbourne, the Belfast-Hamburg, the Jerusalem and the Bronx approaches. ${ }^{3}$

Besides having small differences in the timing and number of interventions, all of these approaches defend the extraction of deciduous

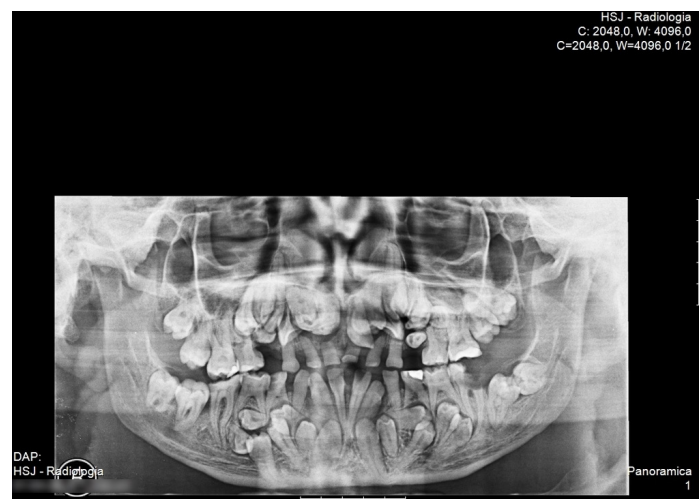

Figure 1 Orthopantomography showing multiple impacted teeth, including supernumerary ones, and a radiopaque mass in the first quadrant.

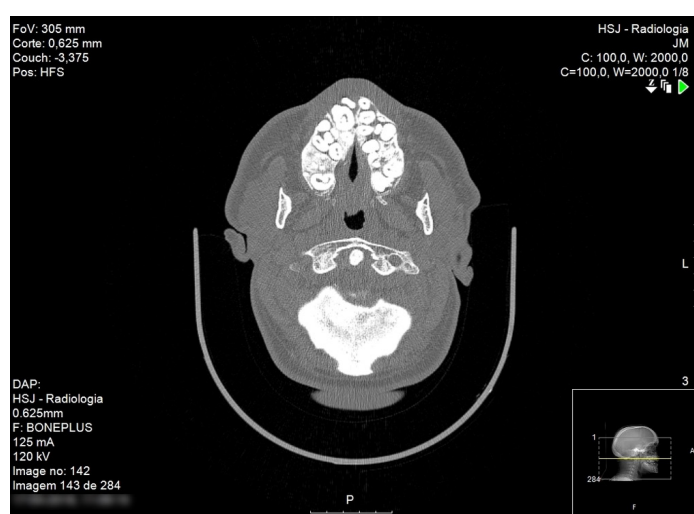

Figure 2 Axial CT demonstrating a well-defined radiopaque mass, surrounded by a radiolucent lesion in the right canine incisor area. Multiple supernumerary teeth.

and supernumerary teeth and orthodontic treatment afterwards. ${ }^{6}$ Several cases need extensive and complex prosthetic rehabilitation. ${ }^{67}$

Because of the complexity of these cases, the management is multidisciplinary and case-by-case oriented. $^{7}$ We did not find any evidence of an approach demonstrating higher rates of success when compared with others.

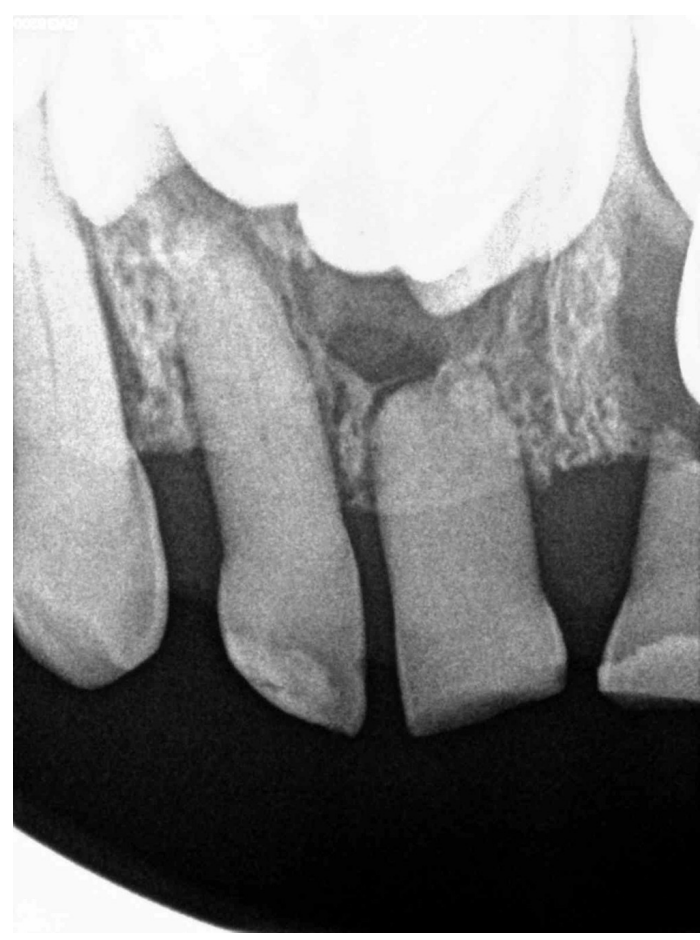

Figure 3 Intraoral X-ray showing the radiolucent lesion extending to the apex of 5.1. 


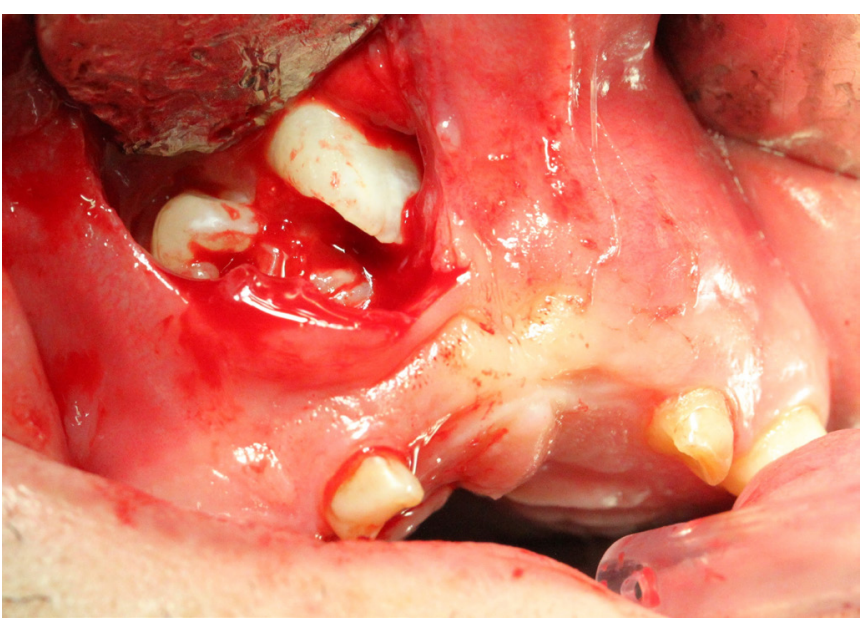

Figure 4 View of maxillary right central incisor (right) and odontoma (left).

A 26-year-old man was referred to our department due to repeated and refractory dental infections and multiple impacted teeth. At time of the appointment, he was under treatment with a beta-lactam antibiotic.

The patient had been diagnosed with CCD since early childhood but, apparently, without dental management. Besides CCD, the patient had no other known conditions. Familywise, there are three more diagnosed cases of CCD (the mother and two siblings).

Intraoral examination showed the presence of early mixed dentition, severe pain on percussion of the tooth 51 and multiple carious lesions.

Panoramic X-ray (figure 1) and CT scan (figure 2) revealed multiple impacted supernumerary teeth and a well limited radiopaque mass, with a radiolucent halo, in the right canine incisor area.

After an intraoral X-ray (figure 3) showing the radiolucent halo extending to the apex of 51 and due to the refractory

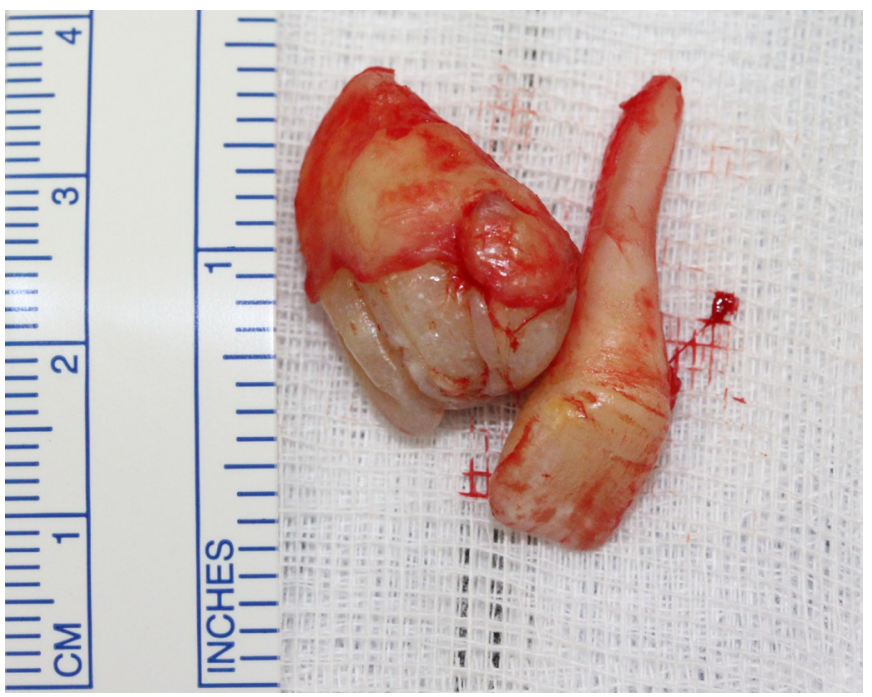

Figure 5 Complex odontoma (left) and right central incisor (right). symptoms, this tooth was extracted with purulent discharge. The curettage of the dental alveolus provided enough material to histopathological examination that showed multiple fragments of epithelium with areas of inflammatory infiltrate compatible with an inflammatory cyst.

Because of the anxiety showed by the patient during oral examination and the uncooperative behaviour for medical treatments reported by him and his mother, he underwent general anaesthesia to extract 52, impacted 11 and a complex OD (figures 4 and 5). Other dental procedures were performed due to the pre-existing carious lesions.

Eight months later, the patient remains asymptomatic.

As previously mentioned, the hyperactivity of the dental lamina promoted the development of supernumerary teeth. ${ }^{4}$ While supernumerary teeth and dental malformations are expected in CCD, the existence of ODs and OD-related infections are less common. 589

Therefore, this is a typical case of CCD associated with an uncommon OD (complex) in an unusual location (maxilla).

\section{Learning points}

- Cleidocranial dysplasia (CCD) is a rare disease, with no universally accepted protocol; hence, it is desirable that the patient should be referred to a multidisciplinary team.

- Dental management should occur since early childhood.

- While supernumerary teeth and dental malformations are expected in CCD, the existence of odontomas (ODs) and ODrelated infections are less common.

Contributors All authors made substantial contributions to the conception and design, acquisition of data, analysis and interpretation of data and participated in drafting the article and revising it. All of them gave the final approval of the version to be submitted and any revised version. No one, other than the authors listed here has contributed substantially to the writing and revising of the manuscript.

Funding The authors have not declared a specific grant for this research from any funding agency in the public, commercial or not-for-profit sectors.

Competing interests None declared.

Patient consent for publication Obtained.

Provenance and peer review Not commissioned; externally peer reviewed.

\section{REFERENCES}

1 Farrow E, Nicot R, Wiss A, et al. Cleidocranial Dysplasia. J Craniofac Surg 2017:1.

2 Shen Z, Zou CC, Yang RW, et al. Cleidocranial dysplasia: report of 3 cases and literature review. Clin Pediatr 2009;48:194-8 https://doi.org/.

3 Impellizzeri A, Midulla G, Romeo U, et al. Delayed Eruption of Permanent Dentition and Maxillary Contraction in Patients with Cleidocranial Dysplasia: Review and Report of a Family. Int J Dent 2018;2018:1-25 https://doi.org/.

4 Pippi R. Odontomas and supernumerary teeth: is there a common origin? Int J Med Sci 2014;11:1282-97 https://doi.org/.

5 Kurt H, Suer T, Ozturk H, et al. The prevalence, anatomic locations and characteristics of the odontomas using panoramic radiographs. Journal of Oral and Maxillofacial Radiology 2015;3:49

6 Berg RW, Kurtz KS, Watanabe I, et al. Interim prosthetic phase of multidisciplinary management of cleidocranial dysplasia: "the Bronx Approach". J Prosthodont 2011;20 Suppl 2:S20-S25.

7 Patel D, Patel N, Brennan PA, et al. Multidisciplinary team approach in the oral rehabilitation of patients with cleidocranial dysplasia to achieve a functional aesthetic outcome. Br J Oral Maxillofac Surg 2017;55:932-6.

8 Lu H, Zeng B, Yu D, et al. Complex dental anomalies in a belatedly diagnosed cleidocranial dysplasia patient. Imaging Sci Dent 2015:45:187-92.

9 Agrawal B, Gharote H, Nair P, et al. Infected complex odontoma: an unusual presentation. Case Rep Child Meml Hosp Chic 2012:2012:bcr2012006493. 
Copyright 2019 BMJ Publishing Group. All rights reserved. For permission to reuse any of this content visit https://www.bmj.com/company/products-services/rights-and-licensing/permissions/

BMJ Case Report Fellows may re-use this article for personal use and teaching without any further permission.

Become a Fellow of BMJ Case Reports today and you can:

- Submit as many cases as you like

- Enjoy fast sympathetic peer review and rapid publication of accepted articles

Access all the published articles

Re-use any of the published material for personal use and teaching without further permission

Customer Service

If you have any further queries about your subscription, please contact our customer services team on +44 (0) 2071111105 or via email at support@bmj.com.

Visit casereports.bmj.com for more articles like this and to become a Fellow 